\title{
miR-381 Attenuates Peripheral Neuropathic Phenotype Caused by Overexpression of PMP22
}

\author{
Ji-Su Lee ${ }^{1}$, Geon Kwak ${ }^{1}$, Hye Jin Kim ${ }^{1}$, Hwan-Tae Park ${ }^{2}$, \\ Byung-Ok Choi ${ }^{1,3 *}$ and Young Bin Hong ${ }^{4 *}$ \\ ${ }^{1}$ Department of Health Sciences and Technology, SAIHST, Sungkyunkwan University, Seoul 06351, ${ }^{2}$ Department of \\ Physiology, College of Medicine, Dong-A University, Busan 49201, ${ }^{3}$ Department of Neurology, Samsung Medical Center, \\ Sungkyunkwan University School of Medicine, Seoul 06351, ${ }^{4}$ Department of Biochemistry, College of Medicine, Dong-A \\ University, Busan 49201, Korea
}

Charcot-Marie Tooth disease type 1A (CMT1A), the major type of CMT, is caused by duplication of peripheral myelin protein 22 (PMP22) gene whose overexpression causes structural and functional abnormalities in myelination. We investigated whether miRNA-mediated regulation of PMP22 expression could reduce the expression level of PMP22, thereby alleviating the demyelinating neuropathic phenotype of CMT1A. We found that several miRNAs were down-regulated in C22 mouse, a CMT1A mouse model. Among them, miR-381 could target 3' untranslated region (3'UTR) of PMP22 in vitro based on Western botting and quantitative Real Time-PCR (qRT-PCR) results. In vivo efficacy of miR-381 was assessed by administration of LV-miR-381, an miR-381 expressing lentiviral vector, into the sciatic nerve of $\mathrm{C} 22$ mice by a single injection at postnatal day 6 (p6). Administration of LV-miR-381 reduced expression level of PMP22 along with elevated level of miR-381 in the sciatic nerve. Rotarod performance analysis revealed that locomotor coordination of LV-miR-381 administered C22 mice was significantly enhanced from 8 weeks post administration. Electrophysiologically, increased motor nerve conduction velocity was observed in treated mice. Histologically, toluidine blue staining and electron microscopy revealed that structural abnormalities of myelination were improved in sciatic nerves of LV-miR-381 treated mice. Therefore, delivery of miR-381 ameliorated the phenotype of peripheral neuropathy in CMT1A mouse model by down-regulating PMP22 expression. These data suggest that miRNA can be used as a potent therapeutic strategy to control diseases with copy number variations such as CMT1A.

Key words: Peripheral myelin protein 22 (PMP22), Demyelination, microRNA (miRNA), Charcot-Marie-Tooth disease (CMT)

Received January 23, 2019, Revised April 5, 2019,

Accepted April 11,2019

\footnotetext{
* To whom correspondence should be addressed. Young Bin Hong, TEL: 82-51-240-2762, FAX: 82-51-240-2971 e-mail:ybhong@dau.ac.kr

Byung-Ok Choi, TEL: 82-2-3410-1296, FAX: 82-2-3410-0052 e-mail:bochoi@skku.edu
}

\section{INTRODUCTION}

Charcot-Marie-Tooth disease (CMT) is one of major inherited peripheral neuropathies with various genetic and clinical heterogeneity [1]. So far, up to 80 genes have been isolated as causative genes [2]. Among them, duplication of peripheral myelin protein 22 (PMP22) (CMT type 1A) which encode a peripheral myelin protein $22 \mathrm{kDa}$ is the major causative gene [3]. Overexpressed PMP22 protein causes demyelination of peripheral nerve through
Copyright $\odot$ Experimental Neurobiology 2019. www.enjournal.org
This is an Open Access article distributed under the terms of the Creative Commons Attribution Non-Commercial License (http://creativecommons.org/licenses/by-nc/4.0) which permits unrestricted non-commercial use, distribution, and reproduction in any medium, provided the original work is properly cited. 
endoplasmic reticulum stress or cell death in Schwann cell [4]. Thus, reducing the expression level of PMP22 is a major strategy to treat CMT1A. So far, therapeutic strategies for treatment of CMT1A have been developed based on indirect manners. For example, progesterone antagonist and vitamin $\mathrm{C}$ have been evaluated in rodent models as potential therapeutic agents with a potency in reducing PMP22 expression level [5-7]. However, these approaches were found to have limited efficacy in human clinical trials $[8,9]$. Therefore, direct manipulation of PMP22 expression might be needed to increase therapeutic benefits.

MicroRNAs (miRNA) are endogenous small noncoding RNAs that are present as RNA-duplex transcripts of approximately 22 nucleotides in length [10]. The significance of regulatory function of miRNAs in development and cellular homeostasis has been demonstrated [11]. During the development of peripheral nervous system, the importance of miRNAs has been investigated. Ablation of Dicer from Schwan cells can block normal myelination and axonal integrity [12-14]. In addition, reduction of Dicer impairs Schwann cell differentiation and myelination [15]. Regarding PMP22 gene expression, several miRNAs such as miR-9 and miR-29b are known to target 3' untranslated region (3'UTR) of PMP22 [16]. Since miRNAs have potency in the management of diseases by regulating the expression level of target mRNAs in eukaryotic cells, targeting PMP22 with its specific miRNA might be a therapeutic option for controlling disease caused by PMP22 overexpression.

Thus, the objective of the present study was to investigate the potency of miRNA as a therapeutic strategy for controlling CMT1A, a disease with copy number variation in peripheral neuropathy. We identified a candidate miRNA whose expression was lowered in CMT1A mouse model. It showed potency in reducing the expression of target gene, PMP22. We also evaluated the potency of miRNA in attenuating the phenotype of CMT1A by regulating the expression level of PMP22 through in vivo study.

\section{MATERIALS AND METHODS}

\section{miRNA sequencing and synthesis}

Expression level of miRNA was evaluated by RNA-sequencing based small RNA sequencing performed by Macrogen, Inc. (Seoul, Korea). TruSeq small RNA library prep kit (Illumina, San Diego, CA, USA) was used after isolating total RNAs from sciatic nerve of wild-type and C22 mice ( $\mathrm{n}=3)$. MicroRNAs and a control miRNA were synthesized by GenePharma (Shanghai, China).

\section{Preparation of PMP22 and miRNAs constructs}

To obtain PMP22 and PMP22-3'UTR, human total mRNA and
gDNA were used as templates for PCR amplification. Amplified gene was cloned into pCMV-myc vector (Clontech, Mountain View, CA, USA). For lentiviral expression of miRNAs, LV-mock (miRNA mimic negative control) and LV-miR381 or miR-9 expression cassette were generated based on lentivirus vector $\mathrm{pLVX}$ IRES-Zsgreen 1 (Clontech, Mountain View, CA, USA). Lentiviral particles were produced in $4.0 \times 10^{6} \mathrm{HEK} 293 \mathrm{~T}$ cells by co-transfection of lentiviral expression plasmids and packaging plasmids from SIRION Biotech (Martinsried, Germany). Supernatant was harvested at $48 \mathrm{~h}$ after transfection. Lentiviral particles were precipitated with polyethylene glycol and dissolved in $400 \mu \mathrm{l}$ serum free CD29 medium (Life Technologies, Carlsbad, CA, USA).

\section{Animals experiments}

All animal experiments were conducted according to protocols approved by the Institutional Animal Care and Use Committees of Samsung Medical Center (SMC-20170203001). C22 mouse [B6;CBACa-Tg(PMP22)C22Clh/H] was purchased from MRC Harwell (Oxfordshire, UK). The C22 mouse is one of the most frequently used mouse model of CMT1A. The mice harbors 7 copies of human PMP22 genes and expression level of hPMP22 is 1.7 fold higher than MPMP22 in the sciatic nerve, which cause severe demyelinating neuropathy within 3 weeks of age [17-21]. Lentiviral particles $\left(7.5 \times 10^{4} \mathrm{IU} /\right.$ mouse $)$ were intraneurally injected distal to the sciatic notch at postnatal day 6 (p6) as previously described [22]. A $10 \mu \mathrm{l}$ Hamilton syringe connected to a 33-gauge needle was used for intraneural injection. Motor coordination was assessed using a Rotarod apparatus (B.S. Technolab INC, Seoul, Korea) with a horizontal rotating rod $(21 \mathrm{rpm})$. The holding time of animals on the rotating rod was measured. Mice were allowed to stay on the rod for a maximum of 300 seconds.

\section{Electrophysiological study}

To assess electrophysiological status, a nerve conduction study (NCS) was performed for wild-type (WT) and C22 mice at 10 weeks post administration as previously described [23]. Briefly, mice were anesthetized with $1.5 \%$ isoflurane supplied using a nose cone for the duration of the procedure. NCS was performed using a Nicolet VikingQuest device (Natus Medical, San Carlos, CA, USA). For measurement of motor nerve conduction velocity (MNCV), the active recording needle electrode (cathode) was placed onto the gastrocnemius muscle with the reference electrode (anode) on its tendon, and the stimulating cathode was perpendicularly inserted approximately $2 \mathrm{~mm}$ under the skin without direct contact to nerve, at the position of $6 \mathrm{~mm}$ proximal to the recording electrode in the midline of the posterior thigh and $6 \mathrm{~mm}$ proximally in the medial gluteal region to obtain distal and proximal re- 
sponses, respectively. The anode was subcutaneously placed in the midline over the sacrum. A surface electrode as a ground electrode placed on the mouse's tail. Finally, single square-wave pulses of 0.1 ms duration were delivered to obtain the conduction signal. Motor nerve conduction velocity (MNCV) and compound muscle action potential (CMAP) amplitudes at supramaximal stimulation were determined by an independent examiner who was blinded to genotype and treatment groups.

\section{Toluidine staining and electron microscopy}

Sciatic nerves were biopsied from both WT and C22 mice at 15 weeks post LV-miR381 administration. Pathological examinations of affected specimens were performed through microscopic analyses. Specimens were fixed overnight with $2.5 \%$ glutaraldehyde in $4 \%$ paraformaldehyde solution at $4{ }^{\circ} \mathrm{C}$. After incubation for $1 \mathrm{hr}$ in $1 \% \mathrm{OsO} 4$, specimens were dehydrated in an ethanol series, passed through propylene oxide, and embedded in epoxy resin (Epok 812, Oken, Japan). Tissues were cut into semi-thin $(1 \mu \mathrm{m})$ sections and stained with toluidine blue for 5 to 10 seconds. Semi-thin sections were imaged using a Bx51 upright microscope (Olympus, Tokyo, Japan) and analyzed using Cell sense (Olympus). Ultrathin sections ( $65 \mathrm{~nm}$ ) were collected on 200 mesh nickel grids and stained with $2 \%$ uranyl acetate for $15 \mathrm{~min}$ and lead citrate for $5 \mathrm{~min}$. These specimens were observed with a Hitachi HT7700 electron microscope at $100 \mathrm{kV}$. About 300 axons were counted per animal.

\section{Quantitative analyses of RNA}

Total RNA was extracted from Schwann cells or sciatic nerves of mice at 15 weeks post administration using RNeasy Mini Kit (Qiagen, Hilden, Germany). After reverse transcription using SuperScript ${ }^{\mathrm{TM}}$ II reverse transcriptase (Thermo Fisher, Rockford, IL, USA), the resulting cDNA was used as template for PCR amplification with the following primers: human PMP22F, 5'-ATCGTCAGCCAATGGATCGTG-3'; human PMP22R, 5'-AGAAACAGTGGTGGACATTTCC-3'; mouse actinF, 5'-GTGACGTTGACATCCGTAAAGA-3'; mouse actinR, 5'-GCCGGACTCATCGTACTCTCC-3'; rat GAPDH-F, 5'-TGCCACTCAGAAGACTGTGG-3'; and rat GAPDH-R, 5'TTCAGCTCTGGGATGACCTT-3'. Real-time PCR reactions were performed using SYBR Green PCR master mix and ABI QuantStudio 6 Flex Real-Time PCR System (Applied Biosystems, Waltham, MA, USA). To quantify levels of miRNA, qRT-PCR was performed using mature miRNA-specific TaqMan primers (Applied Biosystems).

\section{Western blotting and immunohistochemistry}

Total proteins were collected after lysis with RIPA buffer (Bi- osesang, Seoul, Korea) for standard Western blotting. Antibodies used for the determination of proteins of interest were: anti-myc (Abcam, Cambridge, UK), anti-GAPDH, and anti-Rabbit IgG (Cell signaling Technology, Beverly, MA, USA). The band intensity was determined by the Image J program (https://imagej.nih.gov) then normalized to GAPDH. Immunohistochemistry was performed on sliced sections ( $4 \mu \mathrm{m})$ using anti-PMP22 antibodies (Abcam) and Alexa Fluor 594 secondary antibodies (Invitrogen, Life Technologies, Carlsbad, CA, USA). Quantification of protein level was acquired for arithmetic mean intensity with ZEN program.

\section{Statistical analysis}

All values are expressed as mean \pm standard error of the mean (SEM). For pairwise comparisons, statistical significance of data presented was evaluated by Student's t-test. For comparisons of more than 2 treatment groups, statistical significance of data presented was evaluated by 1 -way ANOVA. The level of significance was set at $\mathrm{p}<0.05$.

\section{RESULTS}

\section{Expression levels of myelination-related miRNAs are changed in CMT1A mouse}

To address whether expression levels of miRNAs known to be involved in myelination were changed in CMT1A disease mouse model, the miRNA expression profile was analyzed using RNAsequencing. Expression levels of miR-19b, miR-206, miR-381, and miR-486 in sciatic nerves of C22 mice (CMT1A animal model) were lower than those of wild-type mice (Fig. 1A). On the other hand, expression levels of miR-23a and miR-450a were elevated in C22 mice. Among these miRNAs, we focused on miR-381 because it was previously reported to be one of miRNAs with potency in targeting 3'UTR of PMP22 [16]. Interestingly, expression levels of other miRNAs such as miR-9 and miR29b known to target PMP22 [16] were not dramatically changed in C22 mice. To further confirm next-generation-sequencing (NGS) based profile, we analyzed miR-381 level using quantitative Real Time-PCR and found that expression level of miR-381 in the sciatic nerve of C22 mouse was significantly decreased to $30 \%$ of the control (Fig. 1B).

\section{miR-381 regulates expression level of PMP22 in vitro}

Since miR-381 was previously proposed to target 3'UTR of PMP22, we determined whether miR-381 could regulate PMP22 expression. From miRDB (http://mirdb.org/), a miRNA target prediction database, sequences from c. ${ }^{\star} 995$ to c. ${ }^{\star} 1001$ of 3 'UTR of PMP22 were predicted as the target of miR-381. We generated two plasmids. One contains coding region of human PMP22 while 
the other carries full length of 3'UTR of human PMP22 (Fig. 2A). Using this system, we validated changes at protein expression level after transfection of these vectors into RT4, a rat Schwann cell line. Transfection of miR-381 selectively reduced human PMP22 level when the gene was flanked with 3'UTR (Fig. 2B). Transfection of miR-381 also selectively reduced mRNA level of human
A

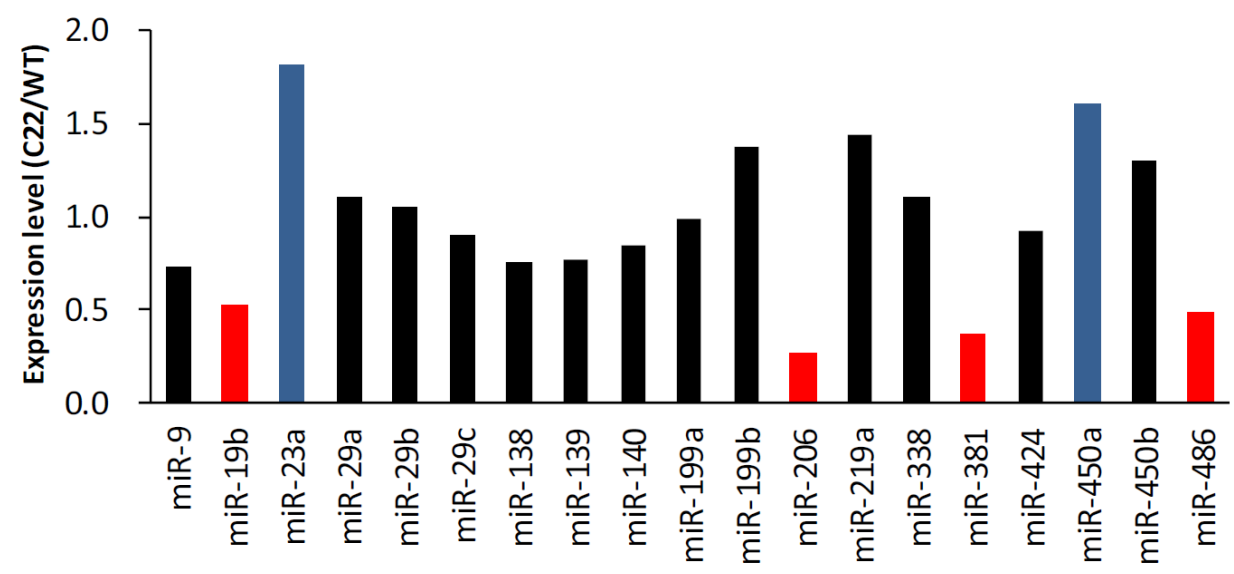

B

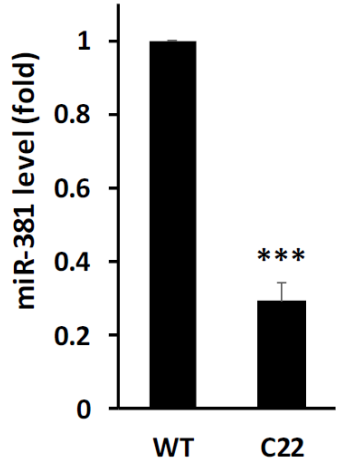

Fig. 1. Expression levels of miRNAs in sciatic nerves of PMP22 overexpressing mice. (A) Expression level of several miRNAs, previously reported to be involved in the development of peripheral nerve or the regulation of mRNA of PMP22 were compared between sciatic nerves of wild-type (WT) and C22 mice using miRNA sequencing. Difference with greater than 50\% were marked by blue (high) or red (low) bars. (B) Expression levels of miR-381 in sciatic nerves of C22 mice were further analyzed by quantitative RT-PCR. ${ }^{* * *} \mathrm{p}<0.001$.

A

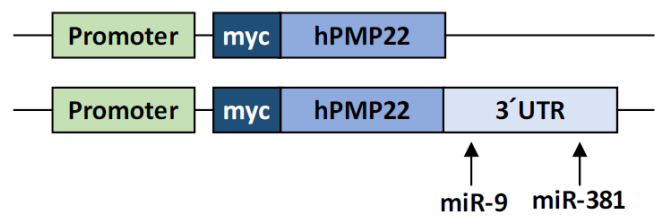

C

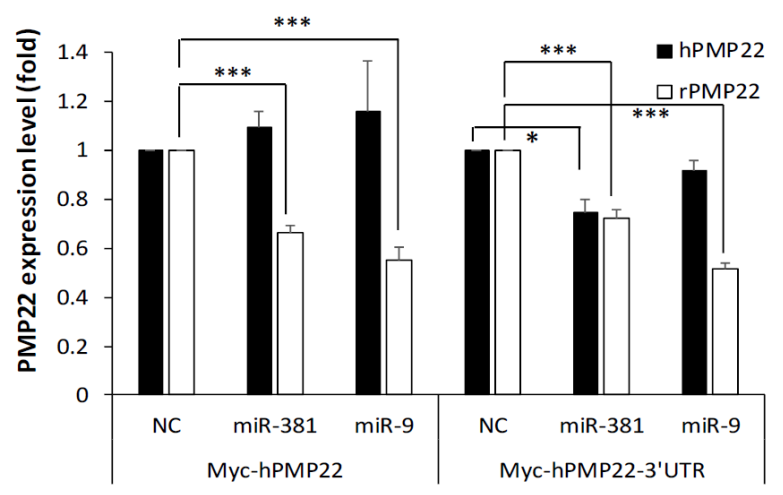

B
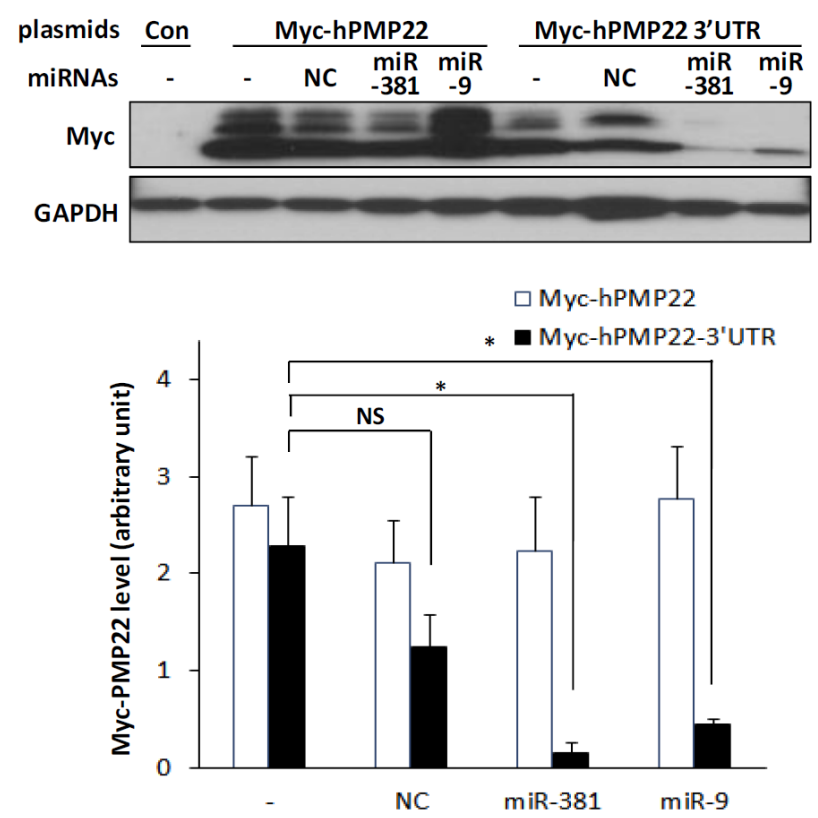

Fig. 2. Effects of miR-381 on PMP22 expression. (A) Schematic diagram of plasmid constructs used to show specificity of miR-381 in targeting the 3'UTR of PMP22 gene. Arrows show target sites of each miRNA. (B) Western blotting showing that miR-381 and miR-9 specifically target the 3'UTR of PMP22. RT4 cells were transfected with either control myc vector (Con), Myc-hPMP22, or Myc-hPMP22-3'UTR vector along with negative control miRNA (mock), miR-381, or miR-9. Quantitation of Western blotting results were displayed (bottom). The band intensity was determined by the Image J program (https://imagej.nih.gov) then normalized to GAPDH. (C) Quantitative RT-PCR analysis showing that miR-381 specifically reduces mRNA level of PMP22 flaked with 3'UTR in the same setting in RT4 cells. ${ }^{*} \mathrm{p}<0.05 ;{ }^{* *} \mathrm{p}<0.01$. 
PMP22 level when the gene was flanked with 3'UTR (Fig. 2C). We also confirmed the alteration of endogenous rat Pmp22 mRNA (rPMP22) level. Since rPmp22 with 3'UTR is expressed in the cell, mRNA level of $r P m p 22$ were also decreased by miR-381 irrespective of overexpression of Myc-hPMP22 or Myc- hPMP22-3'UTR. However, the decreased rate (74.6\% of control) was not so dramatic as the almost complete reduction in protein level (Fig. 2C). Since miR-9 was also reported to target 3'UTR of PMP22 (from c. ${ }^{\star} 435$ to c. $\left.{ }^{\star} 441\right)$ [16, http://mirdb.org/], we evaluated the activity of miR-9 as a positive control and found that transfection of miR9 selectively targeted PMP22 flanked with 3'UTR.

\section{In vivo delivery of miR-381 reduces PMP22 level in sciatic nerve}

Next, we examined whether miR-381 could regulate expression level of PMP22 in sciatic nerves of C22 mice. To deliver miR-381 into the sciatic nerve, we cloned human miR-381 and generated lentiviral particle expressing miR-381 (LV-miR-381) under the control of CMVIE promoter. We then administered LV-miR-381 or control lentiviral vector (LV-mock) into sciatic nerve of C22 mouse model which carries 7 copies of human PMP22 sequence [19]. According to a previous study [24], treatment for the demyelinating neuropathy during the time of myelination in rodents, which begins at postnatal 5 or 6 , resulted in best efficacy. Thus, we attempted to inject LV-miR-381 at p6 to enhance the proper myelination. These mice were genotyped and grouped at 3 weeks of age. To investigate whether lentivirus mediated transfer of miR381 was effectively delivered into sciatic nerve, we first analyzed expression levels of miR-381 in sciatic nerves of C22 mice at 15 weeks post administration. At this time, Wild-type mice complete myelination procedures, while C22 mice cannot walk or stand due to severe demyelination. To obtain the tissues of virus injected region, we collected almost whole length $(\sim 1.5 \mathrm{~cm})$ of the sciatic nerve. qRT-PCR showed that the expression level of miR-381 was significantly increased in LV-miR-381 administered C22 mice compared to that in LV-mock administered mice (Fig. 3A). In line with the elevation of miR-381 level, mRNA levels of human PMP22 were decreased in LV-miR-381 treated C22 mice $(67.0 \%$ of LV-mock treated C22 mice) (Fig. 3B). Since both sequences of miR-381 and 3'UTR of PMP22 were conserved in human and mice to some extent, administration of $L V$-miR-381 reduced mRNA levels of mouse Pmp22 to 51.7\% of LV-mock treated C22 mice (Fig. 3C). In accordance with the reduced mRNA level of PMP22, immunofluorescence analysis also revealed that protein levels of human PMP22 were reduced in sciatic nerves of LVmiR-381 injected C22 mice (45.3\% of LV-mock treated C22 mice) (Fig. 3D).

\section{Physiological and behavioral enhancement by miR-381 in CMT1A mouse}

Next, we examined whether the reduction of PMP22 level by miR-381 was linked to amelioration of abnormal neuropathic phenotype of C22 mice. First, we analyzed the effect on locomotor coordination. Rotarod analysis showed that LV-miR-381 treatment prevented the progression of behavioral deficits which can be observed in C22 mice. C22 mice administered with LVmiR-381 sustained locomotor coordination through 15 weeks of age thereby exhibiting significantly higher performance from 9 weeks of ages ( 8 weeks post administration) (Fig. 4A). To link the enhancement of locomotor coordination in LV-miR-381 treated group to structural and functional improvement of peripheral nerve integrity, we evaluated nerve electrophysiology. Human PMP22 overexpressing C22 mice exhibited slow motor nerve conduction velocity $(\mathrm{MNCV})$ and reduced compound action potential (CMAP) compared to wild-type mice [20]. Administration of LV-miR-381 significantly increased MNCV compared to LVmock treated C22 mice at 10 weeks post administration (Fig. 4B). However, we could not observe significant change in CMAP after administration of LV-miR-381 (Fig. 4C).

We then analyzed histopathological improvement by LVmiR-381 using semi-thin sections of sciatic nerves. Toluidine blue staining revealed that the number of myelinated axons, diameter of axons, and overall thickness of myelination of Schwann cells were decreased in C22 mice treated LV-mock compared to those in wild-type mice treated LV-mock. However, treatment of LVmiR-381 increased the number of myelinated axons and the thickness of myelination in C22 mice. Electron microscopic images also showed enhanced myelination pattern in LV-miR-381 treated mice (Fig. 5A). To quantitatively analyze toluidine blue staining images, we measured g-ratio, the ratio of inner axonal diameter to total outer diameter. Results showed that the g-ratio of LVmiR-381 treated C22 mice had a lower slope than that of LV-mock treated C22 mice, indicating reduction of aberrant myelination by the expression of miR-381 (Fig. 5B). Direct counting revealed that the reduced number of myelinated axon in C22 mice was recovered by expression of miR-381 (Fig. 5C and 5D). In addition, the number of onion bulb formation was reduced in LV-miR-381 administered C22 group (Fig. 5E). However, there was no significant difference in the diameter of myelinated fibers or axons between LV-miR-381 treated C22 mice and LV-mock treated C22 mice, although these diameters were smaller than those of wild-type mice (Fig. 5A and 5B). Collectively, these data indicate that the expression of miR-381 in the sciatic nerve can ameliorate the phenotypic symptoms of CMT1A mouse model. 
A

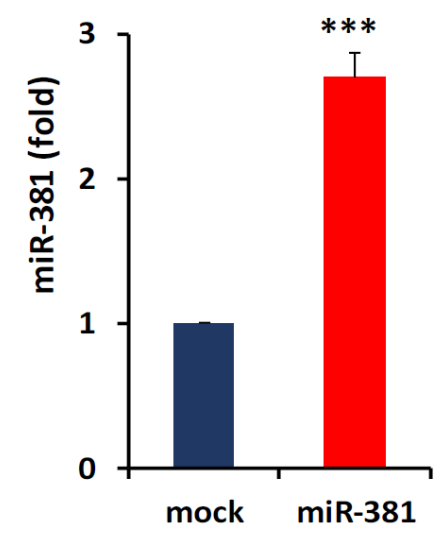

B

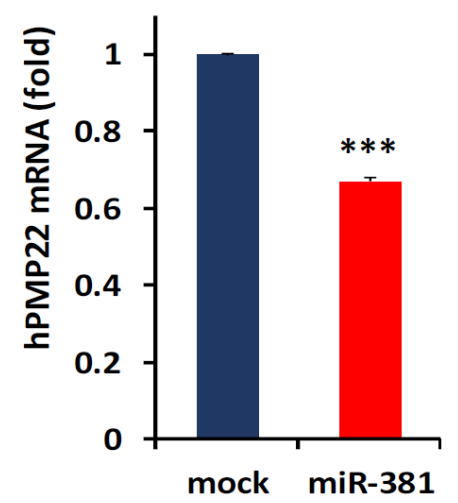

C

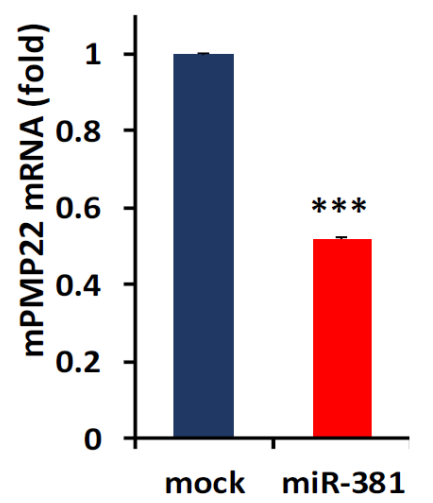

D
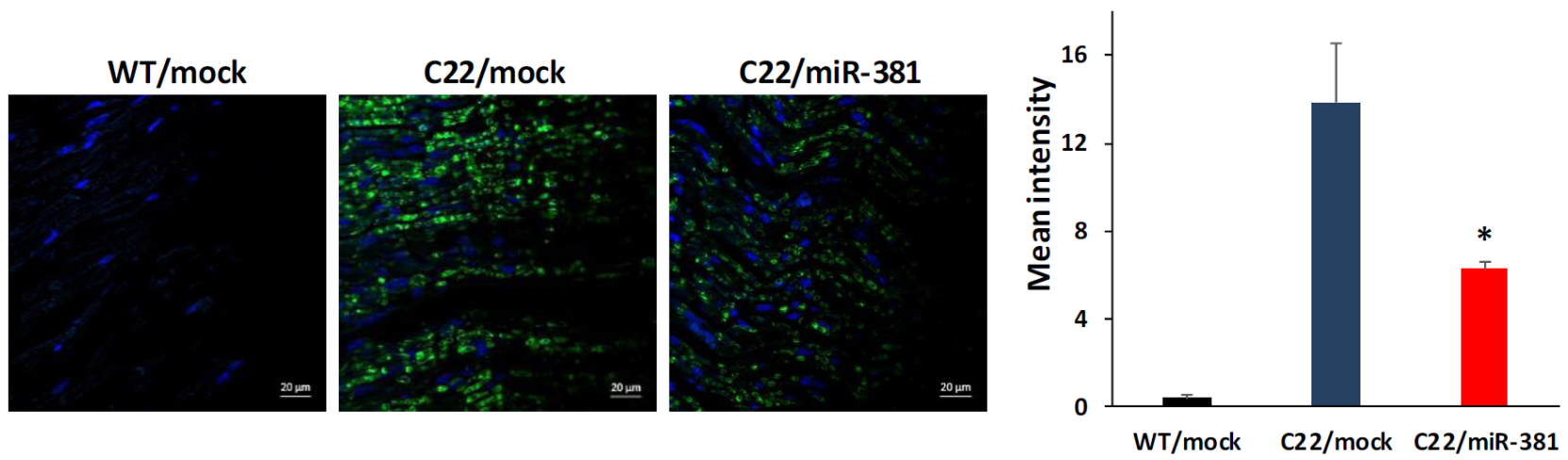

Fig. 3. Quantitation of mRNA and protein levels in sciatic nerves. (A) Quantitative real-time PCR analysis of miR-381 from sciatic nerves of C22 mice at 15 weeks post administration showing efficient delivery of LV-miR-381. (B and C) Quantitative real-time PCR analysis of human PMP22 (B) and mouse Pmp22 (C) showing that the mRNA level was decreased in LV-miR-381 treated C22 mice compared to that in control-miRNA injected C22 mice (mock). (D) Immunofluorescence with human specific PMP22 (green) showing significantly decreased expression level in LV-miR-381 treated C22 mice. Blue, Hoechst staining. ${ }^{*} \mathrm{p}<0.05$.

A

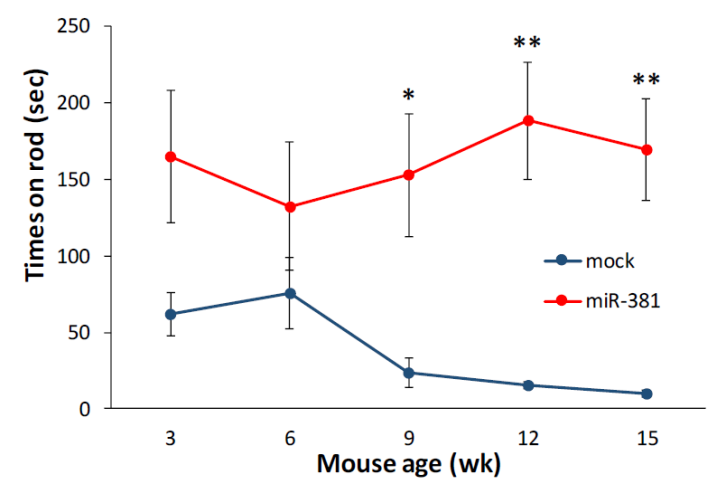

B

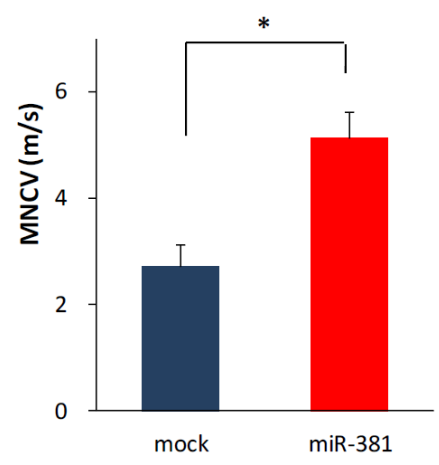

C

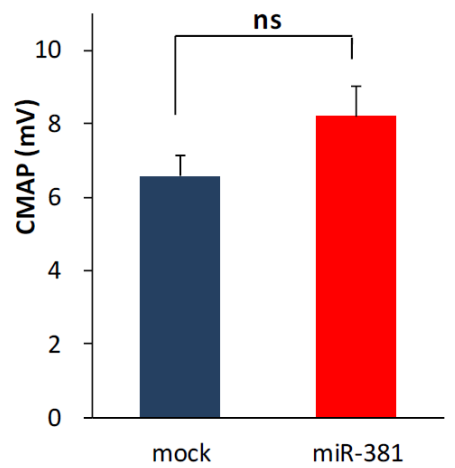

Fig. 4. Enhancement of peripheral phenotype by administration of LV-miR-381. LV-miR-381 $(n=10)$ or LV-mock $(n=6)$ were intraneurally administered to six-day-old C22 mice pups (p6). (A) Rotarod test from 3 weeks of age showing that LV-miR-381 treated C22 mice exhibited significantly increased performance from 9 weeks. (B and C) Nerve conduction study showing increased motor nerve conduction velocity (MNCV) (B) and compound muscle action potential (CMAP) (C) in LV-miR381 administered C22 mice compared to LV-mock treated C22 mice at 10 weeks post administration. ${ }^{*} \mathrm{p}<0.05 ;{ }^{* *} \mathrm{p}<0.01$. 
A

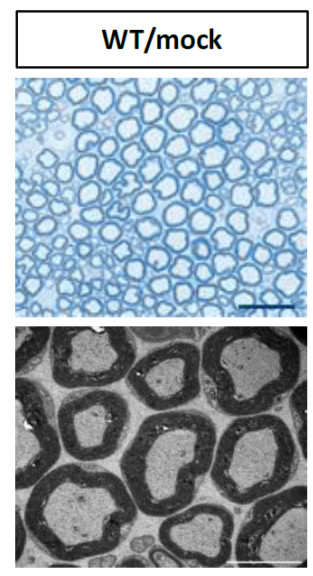

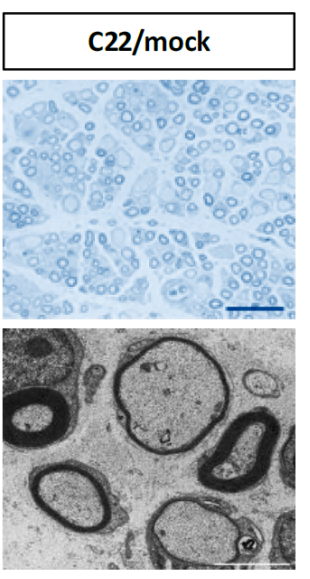

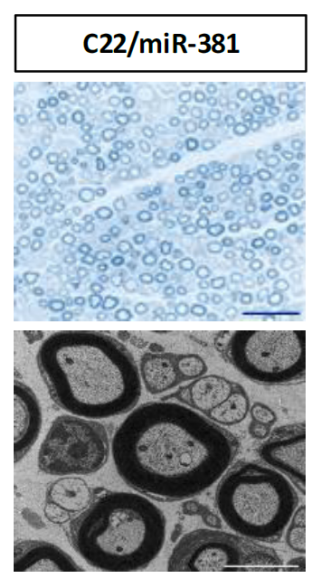

B

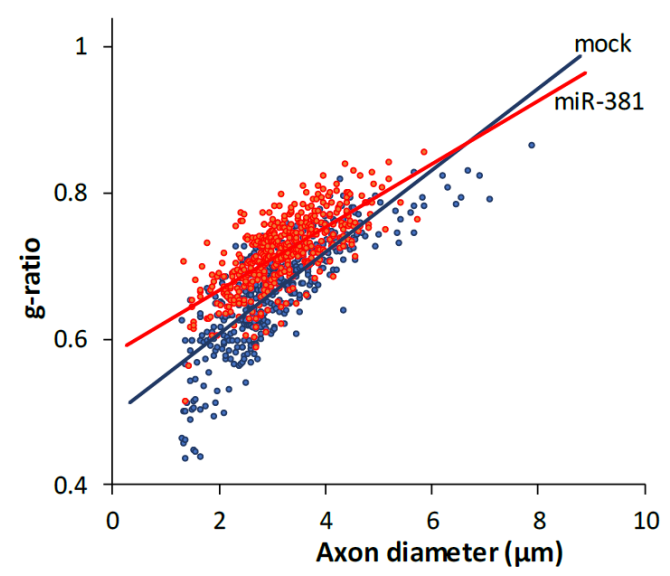

E

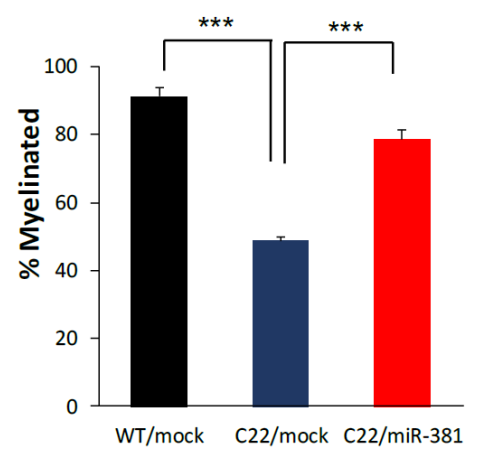

D
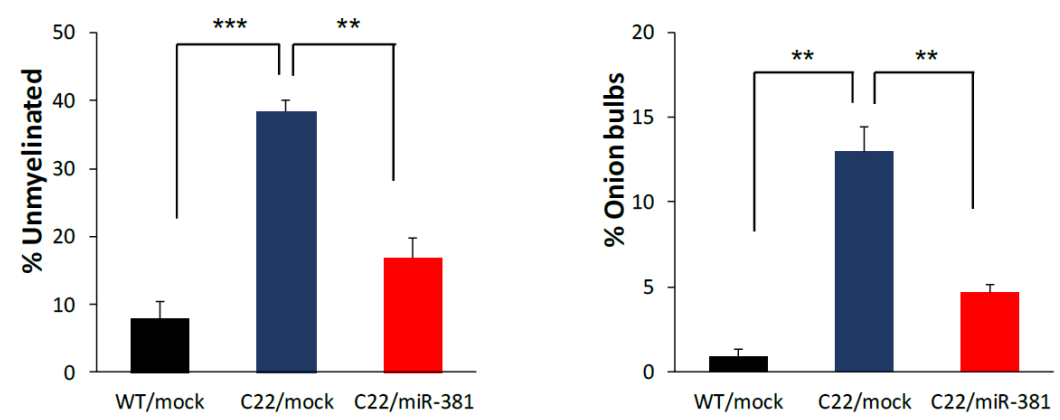

Fig. 5. Enhanced myelination in the sciatic nerve by miR-381. Microscopic images $(\times 200)$ of semi-thin sections and electron microscopic images $(\times 1,500)$ of ultra-thin sections from sciatic nerves of LV-miR-381 or LV-mock treated C22 mice at 15 weeks post administration. Scale bar=20 $\mu$ m for semi-thin for $50 \mu \mathrm{m}$ ultra-thin sections. (B) A scatter plot showing that the g-ratio was improved in LV-miR-381 treated C22 mice. (C E) Quantification of the percentage of myelinated (C) or unmyelinated (D) axons, and onion bulb formation (E). Numbers of myelinated axons and unmyelinated axons were expressed as percentage of total counted axons. Onion bulbs are also expressed as a percentage of total counted axons. ${ }^{* *} \mathrm{p}<0.01$; $^{* * *} \mathrm{p}<0.001$.

\section{DISCUSSION}

In this study, we evaluated the therapeutic feasibility of miRNA in the peripheral neuropathy with copy number variation. We found that the expression level of miR-381 was lower in PMP22 overexpressing mouse model. In addition, miR-381 targeted 3'UTR of PMP22 gene. From these observations, we postulated a therapeutic strategy using miRNA to regulate gene expression of PMP22. In vivo study using mouse model demonstrated that miR-381 expression could successfully decrease PMP22 expression levels, consequently ameliorating the phenotype of peripheral neuropathy in CMT1A mouse model. Analysis of locomotor coordination revealed that expression of miR-381 prevented the progression of behavioral deficits which appear from 3 weeks of age and steadily worsen in C22 mice. Electrophysiological and histopathological data indicated that miR-381 delivery into the sciatic nerve could improve structure and function of peripheral nerves in diseased mice. These data imply that modulation of gene expression is a substantial therapeutic approach to manage diseases caused by copy number variations.

To treat CMT1A, numerous attempts have been made using dietary supplements, growth factors, and chemical drugs. Ascorbic acid has received plausible attentions because of its feasibility and mode of action in reducing PMP22 expression through modulating cAMP level $[6,25]$. However, results from clinical trials on the efficacy of ascorbic acid drugs are questionable [8,9]. Growth factors such as neuregulin and neurotrophin-3 have also been evaluated for their efficacy in the modulation of disease phenotype in relation to improving myelination and axonal integrity [24, 26-28]. Although these approaches have not reached a stage of clinical trials, they might be considered as potent therapeutic options after further development. The advent of systems biology has influenced drug repositioning approaches in CMT treatment. The combination of commercially available drugs (PXT3003) has been 
clinically evaluated in both animal model and patients $[29,30]$. Although these approaches are fundamental strategies to treat genetic diseases, they are based on indirect manipulation of protein expression, facilitation of myelination, or reducing cytotoxicity to nerves. To overcome genetic diseases, more direct approaches might be needed to manipulate duplicated genes. In this context, direct gene manipulation by editing or silencing the duplicated gene is worth trying for CMT1A. It has been recently reported that antisense oligonucleotide (ASO)-based downregulation of PMP22 is effective for rodent models of CMT1A [31]. Although ASO was administered after the onset of the disease, this therapy promoted the recovery of phenotypes of peripheral neuropathy as well as disease-associated gene expression network [31]. Previously, we have evaluated the efficacy of allele-specific small interfering RNA (siRNA) for targeting point mutation in PMP22 [32]. Selective silencing of the mutant-allele alleviated the disease phenotype, including functional and structural improvements of sciatic nerve [32].

To expand therapeutic goals, we investigated the applicability of miRNA to treatment peripheral neuropathy. From the miRNA profile analysis, we found that expression level of several miRNAs such as miR-19b, miR-206 and miR-486 are decreased in sciatic nerve of CMT1A mice. Previously, miR-19b was reported to be consistently reduced during peripheral nerve development [33] and miR-206 is reduced in embryonic stem cells-derived oligodendrocyte differentiation [34]. miR-486 was proposed as a potential therapeutic target through the neuroprotection of NeuroD6 for spinal cord injuries [35]. However, the correlation of these miRNAs with CMT1A or PMP22 has not been reported. Since PMP22-mediated pathogenesis in CMT1A causes apoptosis or abnormal differentiation of Schwann cells in development stages, expression levels of myelination genes or their related genes might be affected in the CMT1A mouse model. Previously, miR-9 was proposed as to modulate the expression level of PMP22 [16]. Thus, we also measured the efficacy of miR-9 in CMT1A mouse model. Mice treated with LV-miR-9 showed similar phenotypic enhancement as mice treated with LV-miR-381 (Supplementary Fig. 1). In this experiment, we did not completely investigate the mode-of-action of miR-381 or miR-9 in the attenuation of CMT1A phenotype and their additional target genes in Schwann cells, however, suppression of PMP22 expression might be proper therapeutic targets for CMT1A. In this context, our present data indicate that miRNA is also a good strategy for gene silencing or detrimental gene expression. Compared with previous allelespecific siRNA study, miRNA showed similar therapeutic effects in the CMT mouse model with minor difference. Our current data revealed that the reduction rate of PMP22 by miR-381 was higher at protein level compared to that at mRNA level in both in vitro and in vivo studies. These data might be due to the manner of miRNA in gene regulation. Compared to the mode of action of siRNA which perfectly forms complementary sequence ( 19 nt) to target mRNA and results in its degradation, miRNA achieve gene silencing mainly by translational regression of mRNA rather than its degradation due to less (6 to 8) nucleotide seed region [36]. In our previous study, we observed no significant difference in the reduction of mRNA or protein level of PMP22-L16P mutant allele by allele-specific siRNA [32]. Therefore, the mode of action in the system might explain the difference in results. In particular, we observed that miRNA treatment had limited effect in improving axonal diameter and CMAP. These results might be due to difference in the administration method. Previously, repeated intraperitoneal injection of synthetic siRNA encapsulated with lipofectamine was applied. In this study, we used lentiviral vector mediated miRNA expression system using intraneural injection to reduce injection time. We knew that intraneural injection could affect the integrity of sciatic nerve. However, we could not observe peripheral nerve damage by 15 weeks post administration. Limited therapeutic effects of miR-381 or miR-9 might be due to difference in target specificity between miRNAs and siRNAs. Although we did not examine global changes of gene expressions after overexpression of miRNAs, additional targets of both miRNAs might be involved in core myelination processes. Therefore, detailed evaluation for any inadvertent side effects is essential before developing miRNAs for future therapeutic options. As soon as unveiling of the mechanistic role of miRNA, there have been steady efforts to apply gene silencing functions of miRNA to clinical strategies. Preclinical studies using miRNA for age-related macular degeneration [37], cardiovascular disease [38, 39], Duchenne muscular dystrophy [40], and malignant tumors $[41,42]$ have been performed.

In conclusion, we demonstrated that miRNA-mediated regulation of gene expression could be applied to treat diseases caused by copy number variation. Further investigations on roles and functions of miRNAs as well as its targets and related genetic environments with the development of its delivery systems might lead to its clinical application in peripheral neuropathy.

\section{ACKNOWLEDGEMENTS}

This study was supported by grants (HI14C3484 and HI16C0426) of the Korean Health Technology R\&D Project funded by the Ministry of Health \& Welfare. It was also supported by grants (NRF-2016R1A5A2007009, NRF-2017R1A2B2004699, and NRF-2018R1A4A1024506) of the National Research Foundation of Korea (NRF) funded by the Ministry of Science and ICT 
(MSIT).

\section{REFERENCES}

1. Skre H (1974) Genetic and clinical aspects of Charcot-MarieTooth's disease. Clin Genet 6:98-118.

2. Pareyson D, Saveri P, Pisciotta C (2017) New developments in Charcot-Marie-Tooth neuropathy and related diseases. Curr Opin Neurol 30:471-480.

3. Boerkoel CF, Takashima H, Garcia CA, Olney RK, Johnson J, Berry K, Russo P, Kennedy S, Teebi AS, Scavina M, Williams LL, Mancias P, Butler IJ, Krajewski K, Shy M, Lupski JR (2002) Charcot-Marie-Tooth disease and related neuropathies: mutation distribution and genotype-phenotype correlation. Ann Neurol 51:190-201.

4. Dickson KM, Bergeron JJ, Shames I, Colby J, Nguyen DT, Chevet E, Thomas DY, Snipes GJ (2002) Association of calnexin with mutant peripheral myelin protein-22 ex vivo: a basis for "gain-of-function" ER diseases. Proc Natl Acad Sci U S A 99:9852-9857.

5. Sereda MW, Meyer zu Hörste G, Suter U, Uzma N, Nave KA (2003) Therapeutic administration of progesterone antagonist in a model of Charcot-Marie-Tooth disease (CMT-1A). Nat Med 9:1533-1537.

6. Passage E, Norreel JC, Noack-Fraissignes P, Sanguedolce V, Pizant J, Thirion X, Robaglia-Schlupp A, Pellissier JF, Fontés M (2004) Ascorbic acid treatment corrects the phenotype of a mouse model of Charcot-Marie-Tooth disease. Nat Med 10:396-401

7. Meyer zu Horste G, Prukop T, Liebetanz D, Mobius W, Nave KA, Sereda MW (2007) Antiprogesterone therapy uncouples axonal loss from demyelination in a transgenic rat model of CMT1A neuropathy. Ann Neurol 61:61-72.

8. Pareyson D, Reilly MM, Schenone A, Fabrizi GM, Cavallaro T, Santoro L, Vita G, Quattrone A, Padua L, Gemignani F, Visioli F, Laurà M, Radice D, Calabrese D, Hughes RA, Solari A; CMT-TRIAAL; CMT-TRAUK groups (2011) Ascorbic acid in Charcot-Marie-Tooth disease type 1A (CMT-TRIAAL and CMT-TRAUK): a double-blind randomised trial. Lancet Neurol 10:320-328.

9. Lewis RA, McDermott MP, Herrmann DN, Hoke A, Clawson LL, Siskind C, Feely SM, Miller LJ, Barohn RJ, Smith P, Luebbe E, Wu X, Shy ME; Muscle Study Group (2013) High-dosage ascorbic acid treatment in Charcot-Marie-Tooth disease type 1A: results of a randomized, double-masked, controlled trial JAMA Neurol 70:981-987.

10. Bartel DP (2004) MicroRNAs: genomics, biogenesis, mecha- nism, and function. Cell 116:281-297.

11. Alvarez-Garcia I, Miska EA (2005) MicroRNA functions in animal development and human disease. Development 132:4653-4662.

12. Bremer J, O'Connor T, Tiberi C, Rehrauer H, Weis J, Aguzzi A (2010) Ablation of Dicer from murine Schwann cells increases their proliferation while blocking myelination. PLoS One 5:e12450.

13. Pereira JA, Baumann R, Norrmén C, Somandin C, Miehe M, Jacob C, Lühmann T, Hall-Bozic H, Mantei N, Meijer D, Suter U (2010) Dicer in Schwann cells is required for myelination and axonal integrity. J Neurosci 30:6763-6775.

14. Yun B, Anderegg A, Menichella D, Wrabetz L, Feltri ML, Awatramani R (2010) MicroRNA-deficient Schwann cells display congenital hypomyelination. J Neurosci 30:7722-7728

15. Verrier JD, Semple-Rowland S, Madorsky I, Papin JE, Notterpek L (2010) Reduction of Dicer impairs Schwann cell differentiation and myelination. J Neurosci Res 88:2558-2568.

16. Verrier JD, Lau P, Hudson L, Murashov AK, Renne R, Notterpek L (2009) Peripheral myelin protein 22 is regulated posttranscriptionally by miRNA-29a. Glia 57:1265-1279.

17. Huxley C, Passage E, Manson A, Putzu G, Figarella-Branger D, Pellissier JF, Fontés M (1996) Construction of a mouse model of Charcot-Marie-Tooth disease type 1A by pronuclear injection of human YAC DNA. Hum Mol Genet 5:563-569.

18. Huxley C, Passage E, Robertson AM, Youl B, Huston S, Manson A, Sabéran-Djoniedi D, Figarella-Branger D, Pellissier JF, Thomas PK, Fontés M (1998) Correlation between varying levels of PMP22 expression and the degree of demyelination and reduction in nerve conduction velocity in transgenic mice. Hum Mol Genet 7:449-458.

19. Robertson AM, Huxley C, King RH, Thomas PK (1999) Development of early postnatal peripheral nerve abnormalities in Trembler-J and PMP22 transgenic mice. J Anat 195:331339.

20. Verhamme C, King RH, ten Asbroek AL, Muddle JR, Nourallah M, Wolterman R, Baas F, van Schaik IN (2011) Myelin and axon pathology in a long-term study of PMP22-overexpressing mice. J Neuropathol Exp Neurol 70:386-398.

21. Chittoor VG, Sooyeon L, Rangaraju S, Nicks JR, Schmidt JT, Madorsky I, Narvaez DC, Notterpek L (2013) Biochemical characterization of protein quality control mechanisms during disease progression in the C22 mouse model of CMT1A. ASN Neuro 5:e00128.

22. Ino D, Iino M (2016) In vivo gene transfer to Schwann cells in the rodent sciatic nerve by electroporation. J Vis Exp 115:e54567. 
23. Lee J, Jung SC, Joo J, Choi YR, Moon HW, Kwak G, Yeo HK, Lee JS, Ahn HJ, Jung N, Hwang S, Rheey J, Woo SY, Kim JY, Hong YB, Choi BO (2015) Overexpression of mutant HSP27 causes axonal neuropathy in mice. J Biomed Sci 22:43.

24. Fledrich R, Stassart RM, Klink A, Rasch LM, Prukop T, Haag L, Czesnik D, Kungl T, Abdelaal TA, Keric N, Stadelmann C, Brück W, Nave KA, Sereda MW (2014) Soluble neuregulin-1 modulates disease pathogenesis in rodent models of CharcotMarie-Tooth disease 1A. Nat Med 20:1055-1061.

25. Kaya F, Belin S, Bourgeois P, Micaleff J, Blin O, Fontés M (2007) Ascorbic acid inhibits PMP22 expression by reducing cAMP levels. Neuromuscul Disord 17:248-253.

26. Sahenk Z, Nagaraja HN, McCracken BS, King WM, Freimer ML, Cedarbaum JM, Mendell JR (2005) NT-3 promotes nerve regeneration and sensory improvement in CMT1A mouse models and in patients. Neurology 65:681-689.

27. Sahenk Z, Galloway G, Edwards C, Malik V, Kaspar BK, Eagle A, Yetter B, Forgie A, Tsao D, Lin JC (2010) TrkB and TrkC agonist antibodies improve function, electrophysiologic and pathologic features in Trembler J mice. Exp Neurol 224:495506.

28. Sahenk Z, Galloway G, Clark KR, Malik V, Rodino-Klapac LR, Kaspar BK, Chen L, Braganza C, Montgomery C, Mendell JR (2014) AAV1.NT-3 gene therapy for Charcot-Marie-Tooth neuropathy. Mol Ther 22:511-521.

29. Attarian S, Vallat JM, Magy L, Funalot B, Gonnaud PM, Lacour A, Péréon Y, Dubourg O, Pouget J, Micallef J, Franques J, Lefebvre MN, Ghorab K, Al-Moussawi M, Tiffreau V, Preudhomme M, Magot A, Leclair-Visonneau L, Stojkovic T, Bossi L, Lehert P, Gilbert W, Bertrand V, Mandel J, Milet A, Hajj R, Boudiaf L, Scart-Grès C, Nabirotchkin S, Guedj M, Chumakov I, Cohen D (2014) An exploratory randomised doubleblind and placebo-controlled phase 2 study of a combination of baclofen, naltrexone and sorbitol (PXT3003) in patients with Charcot-Marie-Tooth disease type 1A. Orphanet J Rare Dis 9:199.

30. Chumakov I, Milet A, Cholet N, Primas G, Boucard A, Pereira Y, Graudens E, Mandel J, Laffaire J, Foucquier J, Glibert F, Bertrand V, Nave KA, Sereda MW, Vial E, Guedj M, Hajj R, Nabirotchkin S, Cohen D (2014) Polytherapy with a combination of three repurposed drugs (PXT3003) down-regulates Pmp22 over-expression and improves myelination, axonal and functional parameters in models of CMT1A neuropathy. Orphanet J Rare Dis 9:201.
31. Zhao HT, Damle S, Ikeda-Lee K, Kuntz S, Li J, Mohan A, Kim A, Hung G, Scheideler MA, Scherer SS, Svaren J, Swayze EE, Kordasiewicz HB (2018) PMP22 antisense oligonucleotides reverse Charcot-Marie-Tooth disease type 1A features in rodent models. J Clin Invest 128:359-368.

32. Lee JS, Chang EH, Koo OJ, Jwa DH, Mo WM, Kwak G, Moon HW, Park HT, Hong YB, Choi BO (2017) Pmp22 mutant allele-specific siRNA alleviates demyelinating neuropathic phenotype in vivo. Neurobiol Dis 100:99-107.

33. Gokey NG, Srinivasan R, Lopez-Anido C, Krueger C, Svaren J (2012) Developmental regulation of microRNA expression in Schwann cells. Mol Cell Biol 32:558-568.

34. Letzen BS, Liu C, Thakor NV, Gearhart JD, All AH, Kerr CL (2010) MicroRNA expression profiling of oligodendrocyte differentiation from human embryonic stem cells. PLoS One 5:e10480.

35. Wang C, Ji B, Cheng B, Chen J, Bai B (2014) Neuroprotection of microRNA in neurological disorders (Review). Biomed Rep 2:611-619.

36. Sontheimer EJ, Carthew RW (2005) Silence from within: endogenous siRNAs and miRNAs. Cell 122:9-12.

37. Askou AL, Alsing S, Holmgaard A, Bek T, Corydon TJ (2018) Dissecting microRNA dysregulation in age-related macular degeneration: new targets for eye gene therapy. Acta Ophthalmol 96:9-23.

38. Karakikes I, Chaanine AH, Kang S, Mukete BN, Jeong D, Zhang S, Hajjar RJ, Lebeche D (2013) Therapeutic cardiactargeted delivery of miR-1 reverses pressure overloadinduced cardiac hypertrophy and attenuates pathological remodeling. J Am Heart Assoc 2:e000078.

39. Sun X, He S, Wara AK, Icli B, Shvartz E, Tesmenitsky Y, Belkin N, Li D, Blackwell TS, Sukhova GK, Croce K, Feinberg MW (2014) Systemic delivery of microRNA-181b inhibits nuclear factor- $\kappa \mathrm{B}$ activation, vascular inflammation, and atherosclerosis in apolipoprotein E-deficient mice. Circ Res 114:32-40.

40. Heller KN, Mendell JT, Mendell JR, Rodino-Klapac LR (2017) MicroRNA-29 overexpression by adeno-associated virus suppresses fibrosis and restores muscle function in combination with micro-dystrophin. JCI Insight 2:e93309.

41. Shah MY, Ferrajoli A, Sood AK, Lopez-Berestein G, Calin GA (2016) microRNA therapeutics in cancer - an emerging concept. EBioMedicine 12:34-42.

42. Ji W, Sun B, Su C (2017) Targeting microRNAs in cancer gene therapy. Genes (Basel) 8:21. 